\title{
The Development of Transformative Agency of Teachers in Teaching Research Activities in China
}

\section{OPEN ACCESS}

Edited by:

Yriö Engeström,

University of Helsinki, Finland

Reviewed by:

Lidia Scifo,

Libera Università Maria SS. Assunta,

Italy

Luxin Yang,

Beijing Foreign Studies University,

China

*Correspondence:

Qiming Mao

qimingmao@mail.ccnu.edu.cn

Jianzhong Hong

jhong@mail.ccnu.edu.cn

${ }^{\dagger}$ These authors have contributed equally to this work and share first authorship

Specialty section:

This article was submitted to Educational Psychology,

a section of the journal

Frontiers in Psychology

Received: 12 June 2021

Accepted: 21 December 2021

Published: 20 January 2022

Citation:

Diao C, Zhou X, Mao Q and Hong J (2022) The Development of Transformative Agency of Teachers

in Teaching Research Activities in China. Front. Psychol. 12:724175.

doi: 10.3389/fpsyg.2021.724175

\begin{abstract}
Chunting Diao ${ }^{1,2 t}$, Xuan Zhou ${ }^{3 \dagger}$, Qiming Mao ${ }^{4 *}$ and Jianzhong Hong ${ }^{1 *}$
${ }^{1}$ School of Psychology, Key Laboratory of Adolescent Cyber Psychology and Behavior, Central China Normal University, Wuhan, China, ${ }^{2}$ School of Humanities, Hubei University of Chinese Medicine, Wuhan, China, ${ }^{3}$ School of Mechanical Engineering, Wuhan Polytechnic University, Wuhan, China, ${ }^{4}$ School of Education, Central China Normal University, Wuhan, China
\end{abstract}

Teaching research activities (TRA) in China are practical and reflective research of teachers on teaching. These required activities are meant to ensure quality education and facilitate the professional development of teachers. However, in TRA, teachers encounter many challenges such as low efficiency and weak team collaboration. These problems make it hard to achieve the expected outcomes. W Primary School reformed its activities using Change Laboratory, a formative intervention approach to workplace learning and development based on activity theory. The data collected included seven recorded meetings in the Change Laboratory. The conversations in the meetings were then transcribed into texts. A deductive method of content analysis was used to code the data, focusing on categorizing comments of teachers about the transformative agency. The findings showed the following: (1) There were five types of transformative agencies, namely, resisting, criticizing, explicating, envisioning, and committing to actions. Resisting and criticizing were represented less frequently, and taking action did not emerge as a type of transformative agency. (2) The comments about transformative agency about tools were more frequent than comments about other elements in the activity system. (3) There were some differences in the expression of transformative agency across participants. At the end of this study, the implications for the development of TRA are discussed.

Keywords: activity theory, change laboratory, elementary school teacher, teaching research activities, transformative agency

\section{INTRODUCTION}

Teaching research activities (TRA) in China are practical and reflective research of teachers on teaching. The method originated from the former Soviet Union and gradually developed its Chinese characteristics. Now, it has become a regular activity for primary school teachers in China. TRA include implementation of curriculum plans, collective preparation for teaching, conducting school-based research activities, and creating open teaching classrooms (Gong, 2014). In recent decades, educational change agents have been trying to facilitate pedagogical innovations among teachers since the implementation of the New Curriculum Reforms in 2001. Under the New Curriculum Reforms of China, "teachers are researchers," and the professional development of 
teachers is increasingly emphasized. Teachers are expected to critically reflect on their activity to improve and develop their teaching practices.

Teaching research activities are assumed to be crucial for ensuring the quality of education of children as well as for facilitating the professional development of teachers. However, teachers have pointed out that they encounter many problems such as low efficiency and weak team collaboration. These problems make it hard to achieve the intended outcomes. Based on the literature, there appear to be three aspects of these problems. First, TRA are from top to down, usually carried out within the framework prescribed by a superior educational administrative department, which makes them lack flexibility in content and form (e.g., Chen, 2012; Li, 2013). Second, the topdown selection of the topics for TRA prioritizes "advanced and novel" topics but ignores practical applications of ideas; TRA do not address the problems that teachers consider most urgent to be solved (e.g., Zhang and Zhao, 2007). Third, the subjectivity of teachers in evaluating TRA and disagreements among teachers about how to accomplish TRA has not been given much attention (e.g., Tan and Fan, 2017).

The transformative agency is essential to TRA. It exists in wider communities and work settings (Engeström, 2015). Based on the activity theoretical framework, the transformative agency has been defined as "breaking away from the given frame of action and taking the initiative to transform it; it is the capacity to form and implement intentions that go beyond and transform the accepted routines and given conditions of an activity" (Virkkunen, 2006; Vänninen et al., 2015). Transformative agency fosters joint activities among teachers as they explain and envision new possibilities through collective interaction over time (Haapasaari et al., 2016). It may be expressed in discourse and understood as a specific type and instrumentality of languagemediated organizational action, in which the participants express and transform a goal (Hall and Seidel Horn, 2012). It can promote change in organizations, and the purpose of TRA is to promote change in the teaching practices.

Change Laboratory (Engeström et al., 1996; Virkkunen and Newnham, 2013) is a formative intervention approach to workplace learning and educational change that builds on activity theory. The method was first implemented in 1995 in Finland. Since then, it has been implemented in work organizations ranging from hospitals and schools to factories and office settings of different countries (Engeström, 2015). It aims at developing generative solutions over long periods in both research activities and the research communities (Sannino et al., 2016). The results of a Change Laboratory are initially local and their diffusion typically takes place as further experimentation, development, and enrichment rather than as direct transfer and multiplication of the created solutions. Change Laboratory provides potential new ways of working that can be envisioned, designed, experienced, and experimented on by a small team through intensive discussion (Virkkunen and Newnham, 2013). A Change Laboratory intervention typically consists of 6 to 12 weekly sessions that last for about $2 \mathrm{~h}$ each. In the Change Laboratory sessions, participants, and researcherinterventionists use a set of representational devices designed for jointly analyzing disturbances and contradictions in their activities and for developing new solutions (Sannino et al., 2016). The emergence and evolution of transformative agency are considered an important outcome of the Change Laboratory (Haapasaari et al., 2016). Change Laboratory interventions can purposefully facilitate transformative agency (Virkkunen and Newnham, 2013). In our research, Change Laboratory is an intervention that helps teachers go through a process of change in their sense of transformative agency and change their skills to enact a new sense of transformative agency. The Change Laboratory supports the transformative agency of teachers and helps us to observe and understand transformative agency through discussions with the participant teachers.

\section{Transformative Agency of Teachers in Teaching Research Activities}

Some researchers point out that the practical participation of teachers in TRA and even leading the process have significant meaning for the growth of teachers (Villegas-Reimers, 2003; Potari, 2013; Gong, 2014). Self-determinism also makes the subjectivity of teachers meaningful. Ryan and Deci (2000) emphasized that when the behavior of an individual is more autonomous, he or she will recognize the role of oneself in transformation more and treat it as important. Accordingly, researchers have also suggested that the motivation and the individual initiative of teachers to participate in activities should be internalized and enhanced (Mushayikwa and Lubben, 2009; Ho et al., 2021). Participation is a central characteristic in situated activity, and it is learning within the practices of the community. Teachers also experience personal development as they engage in these practices (Lave, 1991; Yamagata-Lynch and Haudenschild, 2009). The transformative agency of teachers usually emerges in collective discussions about the classroom community. When teachers create interactional spaces for breaking away from the traditional "taken-for-granted" patterns of activities, they can attain transformative agency (Lipponen and Kumpulainen, 2011; Engeström, 2015). Regarding subjectivity of teachers, since most current TRA are designed and carried out by school management in China, participant teachers are often passive agents of policies and reforms. This may make teachers lack the initiative to participate in TRA. Although many studies have pointed to the important role of participant teachers in change (Sannino, 2010; Gong, 2014), there are limited studies that analyze the change of individual motivation in these activities (Thurlings and den Brok, 2017). Moreover, we should pay attention not only to individual participants but also to their transformative agency, which includes the interconnection and complexity of the local TRA system.

\section{Research on Transformative Agency With Activity Theory}

Activity theory (Engeström, 2008, 2015) explains human activity as an object-oriented, culturally mediated system with six interconnected components: subject, object, tools, community, rules, and division of labor. It aims to explain the collective, transformative processes as part of a complex activity system. In 
an activity system, tools reflect Vygotsky's concept of mediation. They are needed as "auxiliary stimuli" to facilitate breaking away from the problematic or conflicting situation and overcoming "the pull of the past." They can be anything used in the transformation process (Jonassen and Rohrer-Murphy, 1999; Sannino, 2014).

The existing literature on the transformative agency is mostly theoretical, mainly explaining or discussing transformative agency based on activity theory and/or Change Laboratory interventions (Virkkunen, 2006; Haapasaari and Kerosuo, 2015; Tuominen and Lehtonen, 2018). One researcher proposed the concept of radical-transformative agency as a struggle against inequality, economic oppression, racism, and other forms of injustice related to the historical and political contexts of the world-historical struggle (Stetsenko, 2019). A few empirical studies have analyzed expressions of transformative agency as part of the activity system (Vänninen et al., 2015; Haapasaari et al., 2016). Accordingly, some specific types of transformative agencies manifested in talk, such as resisting, criticizing, explicating, envisioning, committing to actions, and taking actions, have been identified (Sannino, 2010; Haapasaari et al., 2016). One study analyzed transformative agency as the quality of expansive learning; in this sense, the transformative agency can be pursued through formative interventions that break away from the confines of the researchers as instructional intentions of interventionists (Sannino et al., 2016). These ideas illuminate transformative agency in developing TRA as an interactive and collective effort that should be examined in a dynamic way (Lund and Eriksen, 2016).

\section{Chinese Culture and the Expression of Transformative Agency}

The Change Laboratory and the discussions with teachers in this study were carried out in China, and this means the characteristics of Chinese communication must be considered. The dominant culture in China is collectivistic. When people express their opinions, they will first consider the feelings of others, and they often use euphemisms or keep silent (Morrison, 2011; Chen, 2012; Tan and Fan, 2017). At the same time, Chinese culture is a typical high-context communication culture, in which most of the information is either in the physical context or is internalized in the person (Hall, 1976). For this reason, too, the expression of transformative agency would be influenced by culture. This issue is something we return to when we discuss our analysis of the Change Laboratory as it was applied to understanding the transformative agency of teachers.

The case study and the Change Laboratory were carried out in W Primary School, located in a city in central China. We analyzed dialogs among teacher participants to gain insight into the transformative agency of teachers. The data collected include seven recorded meetings in the Change Laboratory. They were then transcribed into texts and coded with a categorization of transformative agency expressions (Haapasaari et al., 2016). The questions of interest were as follows: How is the transformative agency of primary teachers expressed and how does it develop in the Change Laboratory discussion of TRA?
The more specific aspects covered in these dialogs were (1) the development of transformative agency of teachers in different stages, (2) the expression of transformative agency about the activity system, and (3) differences in the transformative agency across participants.

\section{MATERIALS AND METHODS}

We conducted a Change Laboratory intervention in $W$ Primary School. The contents, materials, and stimulating tools of every session were planned by the researchers in their roles as interventionists. The participants discussed how to change the content and form of current TRA to make them more efficient. We examined whether teachers showed new expressions of transformative agency and increases in transformative agency throughout these discussions. This was a qualitative and quantitative study. Transcripts of the group discussions were analyzed qualitatively to examine the experiences of teachers with TRA and the emerging expressions of transformative agency. The transcripts were also analyzed quantitatively to assess change in the number and types of expressions of transformative agency over time.

\section{Participants}

The Laboratory participants were young teachers of the school and university researchers. The school is located in a suburb of Wuhan, China. Most students of this school were children of migrant workers, who were not highly educated and had less time and resources to spend on the education of their children than other parents. This meant that teachers invested more time and energy in the education of students than would be the case in other schools. Another feature of the school was the large proportion of young teachers. Because young teachers are more energetic and open than older teachers, the idea of school management was to let the young teachers be the vanguard of reform. Upon the agreement of school management and based on the needs of teachers, our research group proposed the experiment of using Change Laboratory to reform the TRA. A total of ten teachers were selected to participate in the Change Laboratory, considering the spare time of teachers and subjects. Among them, three teachers were replaced after Session 1 because of low participation and an expressed unwillingness to participate in the following meetings.

As shown in Table 1, the final teacher participants included one man and nine women with a mean age of 26 years. Eight of them had bachelor's degree and two had master's degree. They taught a range of subjects: Chinese (five teachers), Math (two teachers), English (two teachers), and Physical education (one teacher). The teachers taught students from grades 2 to 5 . The length of their teaching experience ranged from 0.5 to 6 years, with a mean duration of 1.8 years. In China, the Chinese teacher is usually the headteacher, managing all the affairs of one class. Therefore, the Chinese teacher usually leads only one class. The Math teacher leads two classes. The English teacher leads three classes, and the PE teacher leads eight classes. In W Primary School, the workload of teachers is 14 lessons per week for 
TABLE 1 | The basic information of teacher participants.

\begin{tabular}{|c|c|c|c|c|c|c|c|}
\hline Name & Gender & Age & Education background & Subject & Grade & Length of teaching & Workload (lessons per week) \\
\hline Hui & Female & 26 & Bachelor & Chinese & 4 & 2 & 14 \\
\hline Lin & Female & 28 & Master & Chinese & 5 & 2 & 14 \\
\hline Ting & Female & 27 & Bachelor & Chinese & 4 & 2 & 14 \\
\hline Chen & Female & 28 & Master & Chinese & 5 & 1 & 14 \\
\hline Xin & Female & 23 & Bachelor & Math & 2 & 2 & 14 \\
\hline Lee & Female & 30 & Bachelor & English & 5 & 6 & 18 \\
\hline Ming & Female & 24 & Bachelor & English & 5 & 1 & 18 \\
\hline $\mathrm{Fu}$ & Male & 22 & Bachelor & PE & 4 & 0.5 & 18 \\
\hline Yi & Female & 24 & Bachelor & Chinese & 3 & 2 & 14 \\
\hline Huan & Female & 28 & Master & Math & 5 & 0.5 & 14 \\
\hline
\end{tabular}

Chinese and Math teachers and 18 lessons for English and PE teachers. Each lesson lasts $40 \mathrm{~min}$.

In the Change Laboratory, participants also included six researchers from a university. One of the researchers had a dual role in the project, as the long-time educational expert of the school and researcher of the Change Laboratory. Two researchers controlled the process of the Change Laboratory, including the preparation of stimulus tools and schedule. Another three researchers recorded and videotaped the sessions.

\section{Data Collection}

The data collected in this study include seven discussion sessions held by teachers and researchers by Change Laboratory. These sessions were conducted during November 2018 and January 2019 and were videotaped with the consent of all the participants.

Before every session, a meeting agenda was prepared to ensure that the study procedure was followed, including how to promote the continuation of the discussion from the previous session. In the first two sessions, we noticed that the contributions of teachers were rather short, formal, and polite. The discussions were not very active, perhaps, because teachers did not know each other well and the researchers were new to them. To ease communication, starting with Session 3, we played an icebreaker game before each meeting, which seemed to help.

The discussion session lasted on an average of $126 \mathrm{~min}$ (shortest $=102 \mathrm{~min}$; longest $=153 \mathrm{~min}$ ); the total length of the seven sessions was $854 \mathrm{~min}$. The videotapes were then transcribed verbatim. During transcription, the researchers strived to maintain the original meaning by completely and accurately recording the words spoken, the pauses, and the tone of the interviewees. The transcript contained a total of 1,914 speaking turns.

\section{Data Analysis}

A deductive content analysis was adopted to analyze the data using the conceptual framework of transformative agency suggested by Haapasaari et al. (2016). In this framework, there were six categories of transformative agency, namely, resisting, criticizing, explicating, envisioning, committing to action, and taking action. Deductive content analysis (usually of text data but also paintings, songs, videos, etc.) divides information into meaningful categories and then describes the categories statistically. This method is also called quantitative analysis of qualitative data (Penlington, 2008; Krippendorff, 2018).

As a first step in the analysis, we used the transcripts to identify the six types of the transformative agency listed by Haapasaari et al. (2016) and counted the number of each type. There were 310 expressions of transformative agency in the transcribed data. They were coded according to the types of transformative agency expressions. We selected a speaking turn as a unit of analysis. Some speaking turns contained the necessary information for coding. Some of the speaking turns were difficult to interpret, and these were discussed by the researchers to reach an inter-coder agreement. The six expression types of transformative agency, with respective illustrative excerpts from the data, are presented in Table 2.

As a second step, we took the activity system as a dimension of analysis. The contents of the speaking turns were coded according to the six components of the activity system: subject, object, tools, community, rules, and division of labor. As some speaking turns contained two or more components of the activity, the total number was 332 .

As a third step, we focused on the individual differences and change in transformative agency throughout the sessions. We recorded the frequency with which each participating teacher expressed each of the six types of transformative agency.

\section{RESULTS}

\section{The Development of Transformative Agency}

In the analysis of participant expressions of transformative agency, we found mainly five of the six types as proposed by Haapasaari et al. (2016), namely, resisting, criticizing, explicating, envisioning, and committing to actions. Taking action did not occur because the Laboratory sessions lasted only 3 months, which was not enough time for the whole process of the reform of TRA in W Primary School.

The expression frequencies in each session are presented in Table 3. There were 310 expressions in total. The most frequent expression was envisioning, which numbered 119. The next was explicating new possibilities or potential in the activity, which numbered 104. The other categories were not frequent. There 
TABLE 2 | Six types of the expressions of transformative agency.

\begin{tabular}{|c|c|}
\hline $\begin{array}{l}\text { Type of } \\
\text { expression }\end{array}$ & Identification criteria \\
\hline Resisting & $\begin{array}{l}\text { Resisting the change, new suggestions or initiatives. Directed at } \\
\text { management, co-workers or initiatives. }\end{array}$ \\
\hline Criticizing & $\begin{array}{l}\text { Criticizing the current activity and organization. } \\
\text { Change-oriented and aiming at identifying problems in current } \\
\text { ways of working. }\end{array}$ \\
\hline Explicating & $\begin{array}{l}\text { Explicating new possibilities or potentials in the activity. Relating } \\
\text { to past positive experiences or former well-tried practices. }\end{array}$ \\
\hline Envisioning & $\begin{array}{l}\text { Envisioning new patterns or models in the activity. } \\
\text { Future-oriented suggestions or presentations of a new way of } \\
\text { working. }\end{array}$ \\
\hline $\begin{array}{l}\text { Committing to } \\
\text { actions }\end{array}$ & $\begin{array}{l}\text { Committing to taking concrete new actions to change the } \\
\text { activity. Commissive speech acts tied to time and place. }\end{array}$ \\
\hline Taking action & $\begin{array}{l}\text { Taken consequential actions to change the activity between or } \\
\text { after the laboratory sessions. }\end{array}$ \\
\hline
\end{tabular}

were 50 expressions of criticizing, 24 of resisting, and 13 of committing to actions.

Committing to actions is committing to taking concrete, new actions to change the activity. In our Change Laboratory, teachers mainly explored reform options and then reported them to school leaders. Further action required the consent of school leaders, so there was less commitment to actions. Aside from committing to actions, the least frequent type of expression was resisting. The type of transformative agency usually takes the form of rejecting the suggestions from other participants or sharing their negative experiences. Criticizing was also expressed at low frequency, although it most often highlights the need for a change in the activity (Haapasaari et al., 2016). In the Chinese context, the expressions of resisting and criticizing are always expressed euphemistically, making them hard to distinguish. The researchers likely needed to be involved in the context to understand them. It seemed that they reflected more on the rejection of participants, confusion, and uncertainty about the TRA reform.

As Figure 1 shows, in the earlier two sessions, the expressions of transformative agency focused more on criticizing and explicating. The criticizing gradually declined since Session 1, but explicating, resisting, and envisioning gradually increased. The high point was in Session 3, a turning point from explicating to envisioning. Before Session 3, the expressions of explicating were more frequent than envisioning, while envisioning was more frequent afterward. At the same time, the frequency of resisting began to decline. The transformative agency was weak in the middle and later sessions, reading a low point at Session 5 because the teachers in this session spent more time demonstrating a micro-class example instead of discussing it. It seemed there was a developmental movement from resisting and criticizing toward textitenvisioning.

\section{The Expression of Transformative Agency in an Activity System}

The discussions among the teachers and researchers in the Change Laboratory focused on reform based on making the TRA more efficient. According to activity theory (Engeström, 2015), this reform, as a human activity, has six components. The subject is the teachers whose perspective is adopted. Teachers use tools, such as school resources and self-study guides, to achieve the object of improving the efficiency of the reform activity. The changes in TRA are planned and implemented by a community of teachers within a school. In the Change Laboratory, this community was expanded to include experienced teachers invited from other schools and pedagogical experts from universities. The rules under which reform is enacted include formal and informal conventions, guidelines, contracts, laws, and other societal norms about education. The rules about TRA are now required under the New Curriculum Reform. The division of labor refers to how the teachers share the responsibilities of enacting these reforms.

How often was transformative agency expressed about these six elements of the activity system? The expressions of transformative agency were most common concerning tools: the number was 152 out of 332. The expressions related to other key elements of the activity system were made with the following frequency, in decreasing order: community (61), object (53), subject (40), rules (20), and division of labor (6).

This information was also examined in terms of how often each of the six types of transformative agency (Haapasaari et al., 2016) was expressed about the six elements of the activity system. As shown in Figure 2, envisioning and explicating were much more frequently directed at the tools than at other elements of the activity. The limited expressions of criticizing were mainly about the community, which was relatively hard to change. Although participants had some complaints and criticisms about

TABLE 3 | The expression types of transformative agency.

\begin{tabular}{|c|c|c|c|c|c|c|c|}
\hline Session & $\begin{array}{l}\text { Resisting } \\
f(\%)\end{array}$ & $\begin{array}{c}\text { Criticizing } \\
f(\%)\end{array}$ & $\begin{array}{c}\text { Explicating } \\
f(\%)\end{array}$ & $\begin{array}{c}\text { Envisioning } \\
\qquad(\%)\end{array}$ & $\begin{array}{l}\text { Committing to actions } \\
\qquad f(\%)\end{array}$ & $\begin{array}{c}\text { Taking actions } \\
f(\%)\end{array}$ & $\begin{array}{l}\text { Total } \\
f(\%)\end{array}$ \\
\hline 1 & $4(10.26)$ & $18(46.15)$ & 13 (33.33) & $4(10.26)$ & 0 & 0 & $39(100)$ \\
\hline 2 & $6(12.5)$ & $12(25)$ & $25(53.08)$ & $5(10.42)$ & 0 & 0 & $48(100)$ \\
\hline 3 & $8(11.43)$ & $7(10)$ & $28(40)$ & 27 (38.57) & 0 & 0 & $70(100)$ \\
\hline 4 & $1(2.22)$ & $7(15.56)$ & $11(24.44)$ & 21 (46.67) & $5(11.11)$ & 0 & $45(100)$ \\
\hline 5 & $1(3.7)$ & $1(3.7)$ & $6(22.22)$ & $13(48.15)$ & $6(22.22)$ & 0 & $27(100)$ \\
\hline 6 & 0 & 0 & $4(13.33)$ & 25 (83.33) & 1 (3.33) & 0 & $30(100)$ \\
\hline 7 & $4(7.84)$ & $5(9.8)$ & 17 (33.33) & 24 (47.06) & $1(1.96)$ & 0 & $51(100)$ \\
\hline Total & $24(7.74)$ & 50 (16.13) & 104 (33.55) & 119 (38.39) & $13(4.19)$ & 0 & $310(100)$ \\
\hline
\end{tabular}




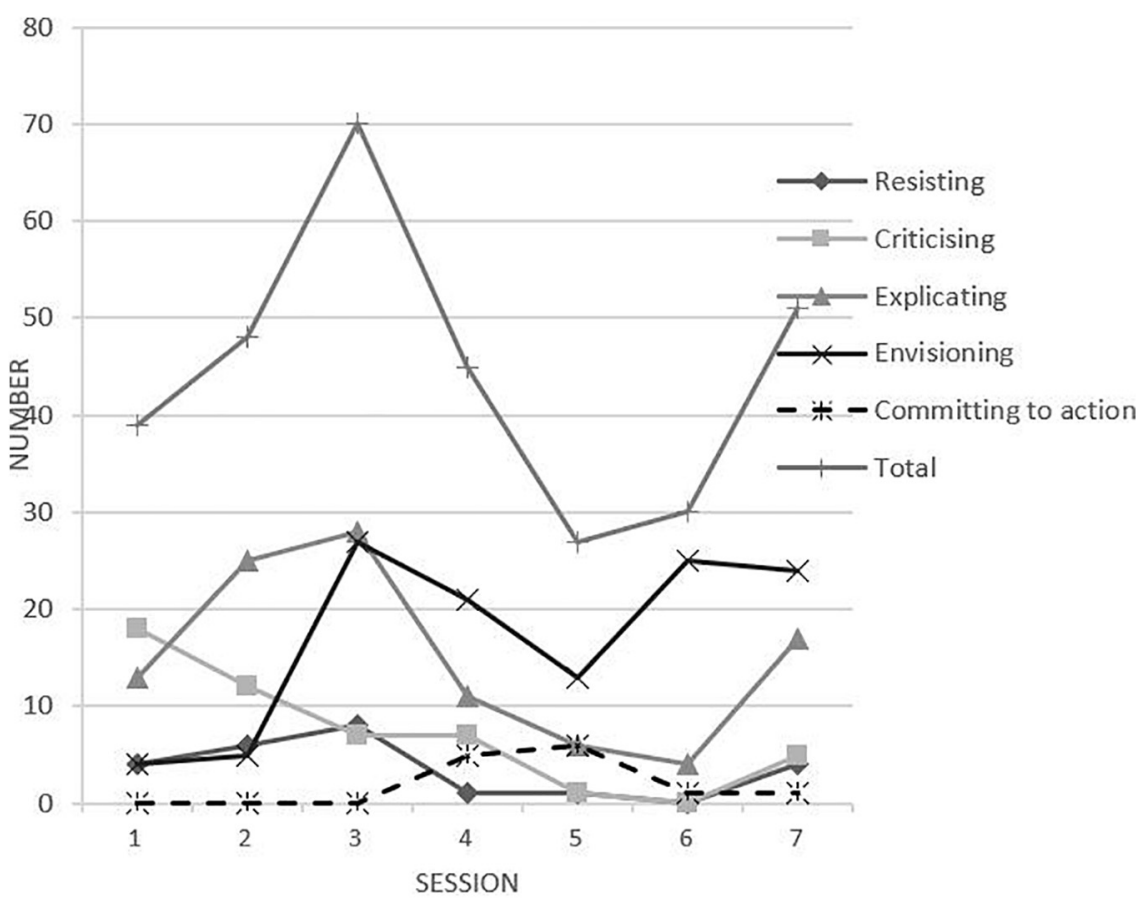

FIGURE 1 | The transformative agency in every session.

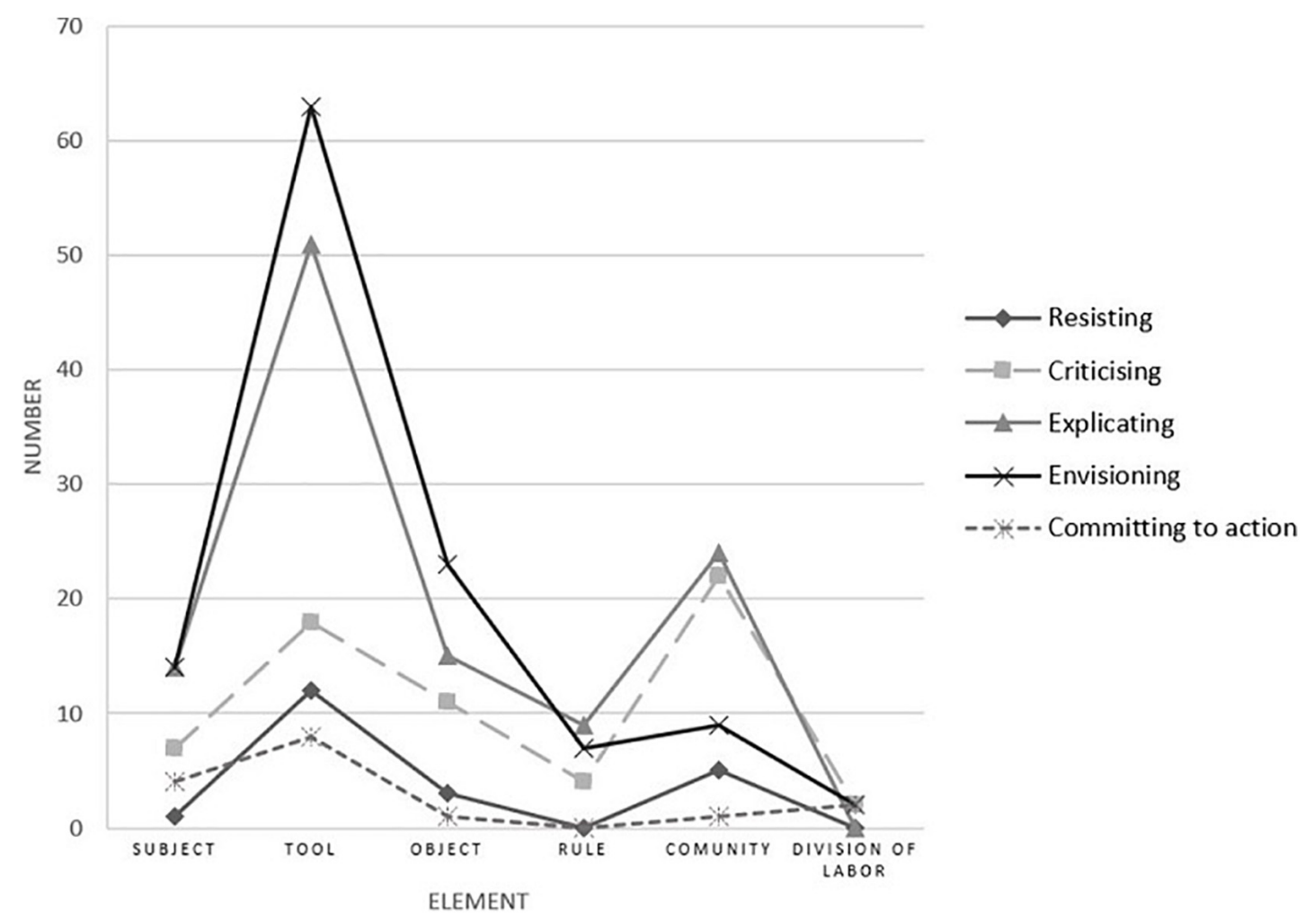

FIGURE 2 | The expression of transformative agency in the activity system. 
the community, they were still hoping to get help from their colleagues, school leaders, and teachers from other schools to reform the current TRA to be more efficient.

\section{The Uneven Contribution of Participants}

The transformative agency differed across the teacher participants. Based on the analysis of its expressions, the participants could be divided into three groups according to the number of speaking turns, namely, (1) Highly active participants, marked with $*$ in Table 4 . Of these, Lee was the most active. She contributed to the largest number of change initiatives. (2) Moderately active participants were Ting, Chen, and Lin. (3) Low active participants were Xin, Fu, Huan, Ming, Lin, and Yi. Table 4 shows that there is a big gap in the number of various expressions among the different types of teachers. Some teacher participants had many experiences and suggestions to share, but after one or two sessions others preferred to be silent and listen to others.

We found that the teacher participants with richer experiences were much more likely to share their opinions. The most typical representative was Lee, the English teacher. She had 6 years of teaching experience. The type she expressed was mainly envisioning, a type that was expressed with much less frequency by the low active participants.

\section{DISCUSSION}

\section{The Expression of Transformative Agency in Chinese Culture}

In our Change Laboratory, the expression of the transformative agency was quite different from previous studies. In previous research on transformative agency, criticizing was the most frequently expressed type (Haapasaari et al., 2016), and resisting the management or the interventionist is also common in the discourse of teachers (Sannino, 2010). By contrast, in our study, criticizing and resisting were the least common types. Explicating was also of relatively low frequency and envisioning was of relatively high frequency.
Several cultural factors might explain these results. In the Chinese collectivist culture, people are not likely to express much criticism and resistance, which may offend the interests of others and negatively affect interpersonal relationships. Chinese culture is relation-based, and in most cases, it is difficult to "only attack the problem, but not the person." People tend to see the topic of communication as intrinsic to the person, if the issue is attacked, so is the person. To avoid interpersonal conflicts, people often choose to be silent during a conversation. Communication in Chinese culture is "listening-centered"; that is, listening is more important than speaking. Mostly, silence is a sign of listening and thinking carefully.

The theory of high- and low-context communication proposed by Hall (1976) highlights this phenomenon by pointing to Chinese culture as a typical high-context communication culture. In such a communication culture, the atmosphere and context are very important when people communicate, and they often also need to pay attention to the meaning expressed by nonverbal cues. Once people are understood, they can relate to others and feel they are in the same community. That is also what we found in our study. When the education experts were explaining the micro-class example, the teachers listened carefully, nodded, and took notes carefully. Then some teachers explained the opinion of an expert in their own words, asking the opinion of an expert to make sure that they really understood it. Whether it is an education expert or a teacher, when explaining, he or she will look at the eyes of other people and other information to see if they understood and then decide if they need further explanation. The result suggests that compared with criticizing and resisting, explicating is more important for envisioning the transformative process in Chinese culture.

\section{The Expressions of Transformative Agency in the Activity System}

The expressions of transformative agency of teachers focused mainly on tools, accounting for $49.4 \%$ of the total expressions. The ratio was significantly higher than other elements of the system in the Laboratory. This is similar to the results proposed by Haapasaari et al. (2016) in which the most discussed topics

TABLE 4 | The number of transformative agency expressions for different participants.

\begin{tabular}{|c|c|c|c|c|c|c|}
\hline Teacher & $\begin{array}{l}\text { Resisting } \\
\qquad(\%)\end{array}$ & $\begin{array}{c}\text { Criticizing } \\
f(\%)\end{array}$ & $\begin{array}{l}\text { Explicating } \\
\qquad f(\%)\end{array}$ & $\begin{array}{c}\text { Envisioning } \\
\qquad f(\%)\end{array}$ & $\begin{array}{l}\text { Committing to action } \\
\qquad f(\%)\end{array}$ & $\begin{array}{l}\text { Total } \\
f(\%)\end{array}$ \\
\hline Lee* $^{*}$ & $6(27.27)$ & $2(4.08)$ & 33 (32.04) & $71(56.80)$ & $6(54.55)$ & 118 (38.06) \\
\hline $\mathrm{Hui}^{*}$ & 2 (9.09) & $14(28.57)$ & 30 (29.13) & $14(11.20)$ & $4(36.36)$ & $64(20.65)$ \\
\hline Ting & $3(13.64)$ & $6(12.24)$ & $5(4.85)$ & $14(11.20)$ & 0 & $28(9.03)$ \\
\hline Chen & $3(13.64)$ & $6(12.24)$ & $5(4.85)$ & $13(10.40)$ & 0 & 27 (8.71) \\
\hline Lin & $4(18.18)$ & 9 (18.37) & $3(2.91)$ & $2(1.60)$ & 1 (9.09) & $19(6.13)$ \\
\hline Xin & $1(4.55)$ & $1(2.04)$ & $8(7.77)$ & $3(2.40)$ & $0(0)$ & $13(4.19)$ \\
\hline $\mathrm{Fu}$ & $2(9.09)$ & $1(2.04)$ & $9(8.74)$ & 0 & 0 & $12(3.87)$ \\
\hline Huan & $0(0)$ & $4(8.16)$ & $4(3.88)$ & $3(2.40)$ & 0 & $11(3.55)$ \\
\hline Ming & 0 & $1(2.04)$ & 3 (2.91) & $5(4.00)$ & $0(0.00)$ & $9(2.90)$ \\
\hline Yi & $1(4.55)$ & $5(10.20)$ & 3 (2.91) & 0 & 0 & $9(2.90)$ \\
\hline
\end{tabular}

*Means that the teacher was a highly active participant. 
related to the transformative agency were the subject $(26 \%)$ and tools $(22 \%)$ of the activity system. In our study, all expression types of the transformative agency had a focus on the tools, especially in the cases of explicating and envisioning. The result of our study is consistent with that of Vänninen et al. (2015).

In the Change Laboratory, the teachers started systematically communicating about TRA issues and tried exploring the ways to solve these problems. The transformative agency of participants focused more on the micro-class example tool, a way of showing teaching, which was first proposed by the researchers in Session 3. The micro-class example helps teachers to capture the problem with a simple idea that can be transformed and expanded into new forms of practice, overcoming the gap between theoretical conception and practice. Participants discussed the application difficulties of the tool. In the beginning, teachers did not know much about it, and there was some criticism and resistance. However, after the attempts in Session 4 and Session 5, teachers had some new ideas of their own about the micro-class example. Of course, the final practical application of the micro-class example is further modified by teachers, which is not the same as what the researchers originally proposed.

Tools help produce qualitative transformations both in individuals and in their environments (Jonassen and RohrerMurphy, 1999; Engeström and Sannino, 2010; Engeström, 2015). For the transformative agency to emerge in an intervention, the subjects must invest in agentive initiatives and volitional actions to transform their activities (Vänninen et al., 2015). In our research, under the influence of culture, people tried to avoid interpersonal conflict in the discussion. The emergence of new tools caused the participants to weigh their desire to change their intentions against their fear of encountering conflicts with others. Discussing tools has much less risk. For both teachers and school leaders, changing tools may bring desirable outcomes for the TRA.

\section{Individual Differences in Transformative Agency}

The development of agency is actively taken up by each individual (Stetsenko, 2019). In the Change Laboratory, although the researchers would encourage everyone to actively participate in the discussion, there were still differences in individual participation. Among the highly active participants, Lee had more teaching experience and insights to share since she has been a teacher for many years, creating a power differential between her and other teacher participants. Hui was the second most active participant (see Table 4). Before entering this school, she worked in another school for 2 years. During the discussion, she shared a lot of previous work experience. Unlike the activity of Lee, her most important expression of change was "interpretation," which compared past positive experiences with current activities.

Among the low-active participants, Ming was a fifth-grade English teacher. Her biggest concern was about the community of the TRA. She also referred to the "apprenticeship system" and "shadow learning" as needing help from the community to transform TRA. These points were related to the identity of
Ming. She was a new teacher who had just been teaching for 1 year, often encountered new situations that were difficult to cope with, and hoped to get targeted guidance. Fu was very motivated to participate in the early stage, but since he was the only physical education teacher in the whole event, there was no discussion between the teachers with the same subject and his feedback did not resonate with the other discussants. He was even absent from some of the later meetings and felt irrelevant to the change activities.

The concept of legitimate peripheral participation provides a way to speak about crucial relations between newcomers and oldtimers, and about their activities, identities, artifacts, knowledge, and practice (Lave, 1991). In group activities, there are bound to be individuals with different levels of activity, but their influence and interaction with each other is the way to establish contact with each other (Ryan and Deci, 2000; Villegas-Reimers, 2003; Thurlings and den Brok, 2017). During the discussion, experienced participants often have more active voices and are more likely to act as problem-solvers. They are proponents and listeners to others who talk about the problem. The activity will be less effective if these experienced teachers do not remain fully engaged in all sessions.

Disparities in the level of participation need particular attention. On the one hand, we should value the participants who have certain experience and are willing to actively try, and encourage them to drive everyone to participate in the change. On the other hand, we should find ways to encourage those who prefer silence to speak up. If the change activity can well meet the needs of individuals and give timely feedback, it will improve the transformative agency of participants. By creating an open and free team atmosphere in the Change Laboratory, participating teachers can freely pursue issues most relevant to them, understand individual needs and expectations of each other, and then try their best to meet their personal development needs in the activities, thus increasing their transformative agency.

\section{DATA AVAILABILITY STATEMENT}

The original contributions presented in the study are included in the article/supplementary material, further inquiries can be directed to the corresponding authors.

\section{AUTHOR CONTRIBUTIONS}

CD contributed to the project administration, writing the original draft, methodology, and data curation. XZ helped in writing the original draft, investigation, and data curation. QM contributed to the conceptualization, methodology, validation, and funding acquisition. $\mathrm{JH}$ contributed to the supervision, writing, reviewing, and editing. All authors contributed to the article and approved the submitted version.

\section{FUNDING}

This study was funded by the Year 2019 General Project Grant of Pedagogy in the 13th Five-Year Plan 
of the National Social Science Foundation of China, "Research on the Operation Mechanism of Famous Teachers' Studios from the Perspective of Modern Apprenticeship" (BHA190122).

\section{REFERENCES}

Chen, J. (2012). Planning, process and evaluation of teaching and research activities. J. Teach. Manage. 11, 33-35.

Engeström, Y. (2008). From Teams To Knots: activity-Theoretical Studies Of Collaboration And Learning At Work. Cambridge: Cambridge University Press. doi: 10.1017/CBO9780511619847

Engeström, Y. (2015). Learning by Expanding: an Activity-Theoretical Approach to Developmental Research, 2nd Edn. Cambridge: Cambridge University Press.

Engeström, Y., and Sannino, A. L. (2010). Studies of expansive learning: foundations, findings and future challenges. Educ. Res. Rev. 5, 1-24. doi: 10. 1016/j.edurev.2009.12.002

Engeström, Y., Virkkunen, J., Helle, M., Pihlaja, J., and Poikela, R. (1996). Change laboratory as a tool for transforming work. Lifelong Learn. Eur. 1, 10-17.

Gong, X. (2014). A Study on the effectiveness of teachers' participation in instructional. Ph.D. thesis. China: Southwest University

Haapasaari, A., Engeström, Y., and Kerosuo, H. (2016). The emergence of learners' transformative agency in a Change Laboratory intervention. J. Educ. Work 29, 232-262. doi: 10.1080/13639080.2014.900168

Haapasaari, A., and Kerosuo, H. (2015). Transformative agency: the challenges of sustainability in a long chain of double stimulation. Learn. Cult. Soc. Interact. 4, 37-47.

Hall, E. T. (1976). Beyond culture. New York: Anchor Press/Doubleday.

Hall, R., and Seidel Horn, I. (2012). Talk and conceptual change at work: adequate representation and epistemic stance in a comparative analysis of statistical consulting and teacher workgroups. Mind Cult. Act. 19, 240-258. doi: 10.1080/ 10749039.2012.688233

Ho, C. S. M., Lu, J., and Bryant, D. A. (2021). Understanding teacher entrepreneurial behavior in schools: conceptualization and empirical investigation. J. Educ. Change 22, 535-564. doi: 10.1007/s10833-020-09406-y

Jonassen, D. H., and Rohrer-Murphy, L. (1999). Activity theory as a framework for designing constructivist learning environments. Educ. Technol. Res. Dev. 47, 61-79. doi: 10.1007/bf02299477

Krippendorff, K. (2018). Content Analysis: an Introduction to Its Methodology, 4th Edn. Thousand Oaks, CA: SAGE Publications, Inc.

Lave, J. (1991). Situated Learning: legitimate Peripheral Participation (Learning in Doing: social, Cognitive and Computational Perspectives) (1st ed.). Cambridge: Cambridge University Press. doi: 10.1017/CBO9780511815355

Li, C. (2013). Problems and improvement strategies in school teaching research activities. Theory Pract. Educ. 33, 18-19.

Lipponen, L., and Kumpulainen, K. (2011). Acting as accountable authors: creating interactional spaces for agency work in teacher education. Teach. Teach. Educ. 27, 812-819. doi: 10.1016/j.tate.2011.01.001

Lund, A., and Eriksen, T. M. (2016). Teacher Education as Transformation: some Lessons Learned from a Center for Excellence in Education. Acta Didact. Nor. 10, 53-72. doi: 10.5617/adno. 2483

Morrison, E. W. (2011). Employee voice behavior: integration and directions for future research. Acad. Manag. Ann. 5, 373-412. doi: 10.1080/19416520.2011. 57450

Mushayikwa, E., and Lubben, F. (2009). Self-directed professional development Hope for teachers working in deprived environments? Teach. Teach. Educ. 25, 375-382. doi: 10.1016/j.tate.2008.12.003

Penlington, C. (2008). Dialogue as a catalyst for teacher change: a conceptual analysis. Teach. Teach. Educ. 24, 1304-1316. doi: 10.1016/j.tate.2007.06.004

Potari, D. (2013). The relationship of theory and practice in mathematics teacher professional development: an activity theory perspective. ZDM Math. Educ. 45, 507-519. doi: 10.1007/s11858-013-0498-2

\section{ACKNOWLEDGMENTS}

The authors thank the leadership and teachers of W Primary School for their support in this research study.

Ryan, R. M., and Deci, E. L. (2000). Self-determination theory and the facilitation of intrinsic motivation, social development, and well-being. Am. Psychol. 55, 68-78. doi: 10.1037/0003-066X.55.1.68

Sannino, A. (2010). Teachers' talk of experiencing: conflict, resistance and agency. Teach. Teach. Educ. 26, 838-844. doi: 10.1016/j.tate.2009. 10.021

Sannino, A. (2014). The emergence of transformative agency and double stimulation: activity-based studies in the Vygotskian tradition. Learn. Cult. Soc. Interact. 4, 1-3. doi: 10.1016/j.lcsi.2014.07.001

Sannino, A., Engeström, Y., and Lemos, M. (2016). Formative interventions for expansive learning and transformative agency. J. Learn. Sci. 25, 599-633. doi: 10.1080/10508406.2016.1204547

Stetsenko, A. (2019). Radical-transformative agency: continuities and contrasts with relational agency and implications for education. Front. Educ. 4:148. doi: $10.3389 /$ feduc. 2019.00148

Tan, T., and Fan, W. (2017). Absence and Return of Interaction of School-based Teaching and Research Subject. J. Chin. Educ. 01, 79-84.

Thurlings, M., and den Brok, P. (2017). Learning outcomes of teacher professional development activities: a meta-study. Educ. Rev. 69, 554-576. doi: 10.1080/ 00131911.2017 .1281226

Tuominen, T. M., and Lehtonen, M. H. (2018). The emergence of transformative agency in professional work. Organ. Stud. 39, 1601-1624. doi: 10.1177/ 0170840617717093

Vänninen, I., Pereira-Querol, M., and Engeström, Y. (2015). Generating transformative agency among horticultural producers: an activity-theoretical approach to transforming integrated pest management. Agric. Syst. 139, 38-49. doi: 10.1016/j.agsy.2015.06.003

Villegas-Reimers, E. (2003). Teacher Professional Development: an International Review of the Literature. Paris: IIPE-UNESCO.

Virkkunen, J. (2006). Dilemmas in building shared transformative agency. Activités 3, 43-66. doi: 10.4000/activites. 1850

Virkkunen, J., and Newnham, D. S. (2013). The Change Laboratory: a tool for collaborative development of work and education. Rotterdam: Sense Publishers. doi: 10.1007/978-94-6209-326-3

Yamagata-Lynch, L. C., and Haudenschild, M. T. (2009). Using activity systems analysis to identify inner contradictions in teacher professional development. Teach. Teach. Educ. 25, 507-517. doi: 10.1016/j.tate.2008.09.014

Zhang, W., and Zhao, L. (2007). Problems and countermeasures of school-based teaching and research in current primary and secondary schools. Educ. Res. 6, 69-73.

Conflict of Interest: The authors declare that the research was conducted in the absence of any commercial or financial relationships that could be construed as a potential conflict of interest.

Publisher's Note: All claims expressed in this article are solely those of the authors and do not necessarily represent those of their affiliated organizations, or those of the publisher, the editors and the reviewers. Any product that may be evaluated in this article, or claim that may be made by its manufacturer, is not guaranteed or endorsed by the publisher.

Copyright (c) 2022 Diao, Zhou, Mao and Hong. This is an open-access article distributed under the terms of the Creative Commons Attribution License (CC BY). The use, distribution or reproduction in other forums is permitted, provided the original author(s) and the copyright owner(s) are credited and that the original publication in this journal is cited, in accordance with accepted academic practice. No use, distribution or reproduction is permitted which does not comply with these terms. 